\title{
Preparation of hollow PCL microspheres by o/w single emulsion-solvent evaporation method in the presence of graphene nanopowders
}

\author{
A. M. Deliormanll ${ }^{*}$, A. C. Yenice \\ Manisa Celal Bayar University, Metallurgical and Materials Engineering Department, 45140 Yunusemre, Manisa, Turkey
}

Received 23 October 2020; accepted in revised form 21 January 2021

\begin{abstract}
Poly- $\varepsilon$-caprolactone (PCL) microspheres containing graphene nanopowders were prepared by oil-in-water (o/w) emulsion solvent- evaporation technique. For the emulsification study, an oil phase (PCL solution in dichloromethane or chloroform) and a water phase (3 $\mathrm{wt} \%$ aqueous polyvinyl alcohol solution) was utilized. Effect of solvent type, stirring speed, and graphene addition on the structural and morphological properties of the prepared microspheres was investigated. Results showed that stable emulsification of oil in water $(\mathrm{o} / \mathrm{w})$ was achieved with a $5 \mathrm{wt} \%$ PCL. A decrease in particle size was observed for the PCL microspheres prepared by chloroform $(19.02 \pm 6.41 \mu \mathrm{m})$ compared to the microspheres obtained by dichloromethane $(59.81 \pm 23 \mu \mathrm{m})$ under the same conditions. Results also revealed that the addition of graphene changed the morphology and particle size of the microspheres significantly. Hollow PCL microspheres were obtained in the presence of graphene nanopowders when chloroform was utilized as the solvent. Drug release experiments indicated that hollow PCLgraphene composite microspheres have improved release behavior compared to bare solid PCL microspheres. The particles prepared in the study have the potential to be used in drug delivery and tissue engineering applications.
\end{abstract}

Keywords: biopolymers, polycaprolactone, graphene, microspheres, drug release

\section{Introduction}

Synthetic polymeric microspheres have widespread usage in biomedical applications. They can be utilized as fillers, bulking agents, flow indicators, or in drug-delivery systems $[1,3]$. Microspheres are defined as spherical particles ranging from $1-1000 \mu \mathrm{m}$. They can be produced in the form of solid or hollow morphology using a variety of techniques, including emulsification approach with single or double solvent evaporation [2-4], sedimentation polymerization [1], spray-drying [5], electrospraying or phase separation technique [3].

PCL is a biodegradable, biocompatible, and waterinsoluble synthetic polymer [6]. The PCL-based microspheres have been used for different applications both in bone and soft tissue engineering, including drug delivery systems for the controlled release of pharmaceutical products due to their slow degradation, which is ideally suitable for the long-term delivery of drugs and proteins [6-9].

Additionally, the preparation of PCL-based composite microspheres has been reported in the literature. Kim and Koh [10] studied the synthesis of aligned porous PCL/hydroxyapatite (HA) bio-composite microspheres. It was reported that the size of the PCL microspheres increased from $62 \pm 7$ to $179 \pm 95 \mu \mathrm{m}$ in the presence of HA (at $20 \mathrm{wt} \%$ ). The inclusion of HA particles to the PCL polymeric matrix caused a significant enhancement of in vitro bioactivity in simulated body fluid [10]. Similarly, Shin et al. [11] manufactured PCL microspheres in the presence of magnesium hydroxide with improved physicochemical 
and biological performance. Results showed that the $\mathrm{PCL} /$ magnesium hydroxide microspheres have a high potential to be used as a dermal filler for skin and facial plastic surgery. Similarly, Wang et al. [12] developed an accurate method to synthesize the PCL/ magnetic $\left(\mathrm{CoFe}_{2} \mathrm{O}_{4}\right)$ composite microspheres in the presence of 5-Fluorouracil. The prepared drug-loaded material system showing magnetic properties was considered as an effective anticancer drug model [12]. Besides solid microspheres, the fabrication of hollow polymeric microspheres has been studied previously [13-15]. It was reported that the hollow microspheres have lower density and higher surface area compared to the solid microspheres. They can be used in a wide range of potential applications, such as the controlled local delivery of drugs and proteins [13, 14]. Despite of the extensive research on the preparation of hollow microspheres, studies on the preparation of PCL hollow microspheres are limited $[16,17]$.

Similarly, carbon-based nanomaterials such as carbon nanotubes, graphene, graphene oxide, and reduced graphene oxide have attracted great attention in the preparation of polymer composites for biomedical applications. The building block of these carbonbased nanomaterials is a layer of $\mathrm{sp}^{2}$ hybridized carbon atoms covalently bonded in a honeycomb lattice $[18,19]$. Among them, graphene is reported to have excellent electrical, mechanical, and thermal properties, which makes it ideal for high-performance biomedical applications [20]. Previously, some studies have been conducted on the preparation of graphenePCL composites in the form of scaffolds using solvent casting- particulate leaching and three-dimensional printing methods [21-23]. Results of these studies pointed out that graphene-containing PCL scaffolds are not cytotoxic to pre-chondrogenic ATDC-5 and bone marrow mesenchymal stem cells. It was reported that PCL-based graphene-containing bio-composite scaffolds had improved mechanical properties, high electrical conductivity, and they are promising materials to use as conducting substrates for the electrically stimulated growth of cells in biotechnological applications [21-23].

Although there is extensive research on the use of graphene nanostructures in PCL matrix composites, their effect on the preparation of PCL-based microspheres has not been investigated. Therefore, the aim of this work was to develop biocompatible PCL microspheres for biomedical applications using graphene nanopowders.

\section{Materials and methods}

\subsection{Materials}

Poly( $\varepsilon$-caprolactone), PCL $\left(M_{\mathrm{n}}: 80000 \mathrm{~g} / \mathrm{mole}\right)$ was purchased from Sigma-Aldrich, USA. Poly(vinyl alcohol) (PVA) ( $M_{\mathrm{w}}$ : 88 000-97 000, 88\% hydrolyzed, Alfa Aesar), dichloromethane (DCM), and chloroform (CHF) (Sigma-Aldrich, St. Louis, USA) was utilized as received. Graphene nanopowders in the form of flakes (Grade AO-4) were obtained from Graphene Laboratories Inc., USA. Average flake thickness and the particle (lateral) size were reported to be $60 \mathrm{~nm}$ and 3-7 $\mu \mathrm{m}$, respectively, by the manufacturing company. Amoxicillin $\left(\mathrm{C}_{16} \mathrm{H}_{19} \mathrm{~N}_{3} \mathrm{O}_{5} \mathrm{~S}, M_{\mathrm{w}}\right.$ : 365.4) was purchased from Merck, Germany.

\subsection{Microsphere preparation}

PCL microspheres were prepared by oil-in-water $(\mathrm{o} / \mathrm{w})$ single emulsion-solvent evaporation method. The method mainly consists of two steps, namely emulsification and solvent evaporation. After the emulsion is prepared, evaporation of the solvent is performed, which causes a shrinkage of the droplets according to the solvent-polymer ratio [24].

In the study, $5 \mathrm{wt} \%$ PCL solutions were prepared in dichloromethane or chloroform at room temperature, and PVA solutions ( $3 \mathrm{wt} \%$ ) were prepared by deionized water at $50{ }^{\circ} \mathrm{C}$ using a magnetic stirrer. For the emulsification study, the oil phase $(5 \mathrm{wt} \%$ PCL solution) was loaded to a $20 \mathrm{ml}$ syringe, which was connected to a micro-pump. The oil phase was added dropwise $(2 \mathrm{ml} / \mathrm{h})$ to the aqueous phase containing $3 \mathrm{wt} \% \mathrm{PVA}$ in water through stirring at 350 or $1500 \mathrm{rpm}$ for 3 hours at room temperature. The distance between the surface of the water phase and the initial PCL solution droplets was set at $7 \mathrm{~cm}$ through the experiments. The resulting emulsion was gently stirred at $350 \mathrm{rpm}$ for further 15 hours until the organic solvent is removed by evaporation and leading to the formation of solid PCL microspheres. Subsequently, the PCL microspheres were filtered using a separation funnel in the presence of a filter paper and washed with deionized water to remove traces of organic solvent, followed by drying at room temperature for 48 hours prior to characterizations. The method used in microsphere preparation is shown schematically in Figure 1. In this technique, through 


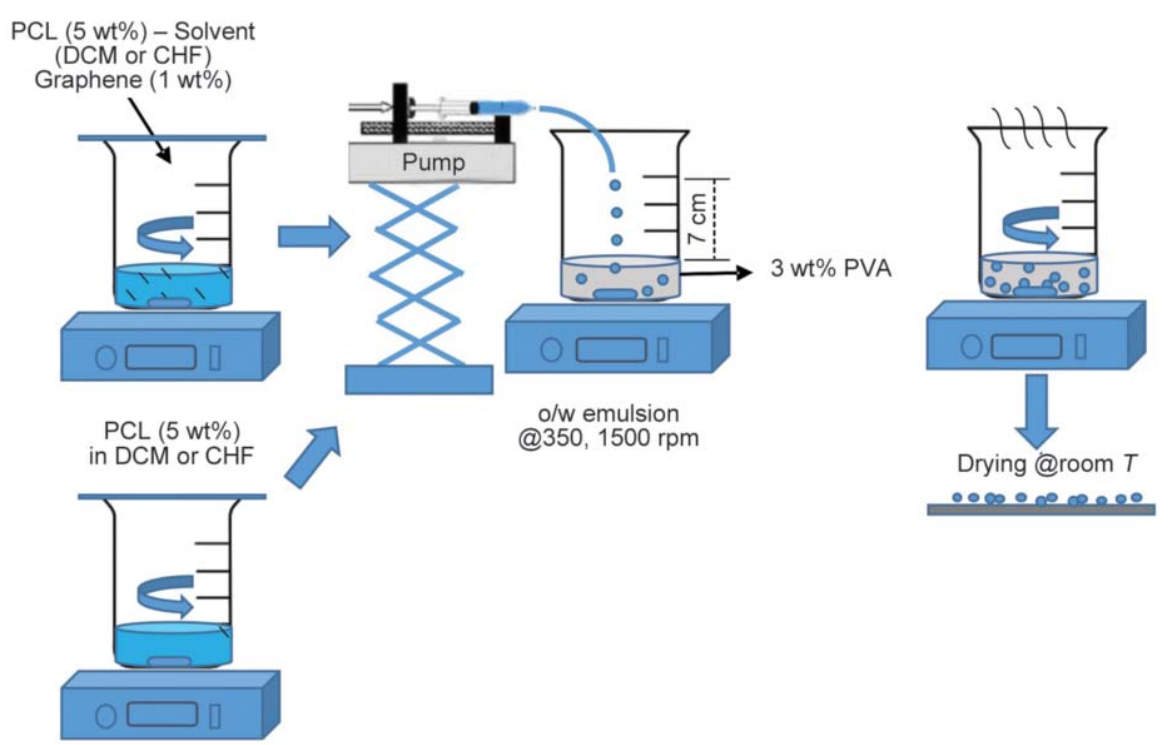

Figure 1. Schematic illustration of the method utilized in bare and graphene-containing PCL microsphere fabrication.

evaporation of the organic solvent from the droplets, the concentration of the polymer increases and reaches a critical value at which the polymer concentration exceeds its solubility limit in the organic phase followed by precipitation of the microspheres [3, 25]. In the study, for the preparation of graphene-PCL composite microspheres prior to emulsification, graphene nanopowders (at $1 \mathrm{wt} \%$ ) were added to the $5 \mathrm{wt} \%$ PCL solution and homogenized using an ultrasonic probe (Bandelin, Sonopuls, Germany) at a peak to peak amplitude of $191 \mu \mathrm{m}$ for 10 minutes followed by magnetic stirring for 15 minutes at $350 \mathrm{rpm}$. Subsequently, the PCL dispersion in the presence of graphene nanopowders was introduced into the water phase solution using conditions described previously. The bare and graphene-containing PCL microspheres prepared using dichloromethane and chloroform were designated as PCL-DCM, PCL-CHF, PCL-DCM-G and PCL-CHF-G, respectively.

\subsection{Characterizations}

The morphology of the prepared bare and graphenecontaining PCL microspheres was investigated using scanning electron microscopy, SEM (Philips XL-30S FEG; Eindhoven, Netherlands). Prior to analysis, samples were sputter-coated with gold/palladium. The analysis was made at an accelerating voltage of $3 \mathrm{keV}$ and a working distance of $10 \mathrm{~mm}$.

The particle size of the prepared microspheres was measured based on the SEM micrographs. For this purpose, images of at least 50 microspheres were selected randomly and measured using Image J software, and results were averaged.

Structural properties of the prepared samples were investigated using Fourier Transform Infrared Spectroscopy with attenuated total reflection accessory, FTIR-ATR (Perkin Elmer, Spectrum 2). Measurements were performed in the wavenumber range of $400-4000 \mathrm{~cm}^{-1}$.

\subsection{Drug release experiments}

Amoxicillin was utilized in drug release experiments. A phosphate-buffered saline solution (PBS) was prepared using $\mathrm{NaCl}, \mathrm{KCl}, \mathrm{Na}_{2} \mathrm{HPO}_{4}$, and $\mathrm{KH}_{2} \mathrm{PO}_{4}$. Initial $\mathrm{pH}$ adjustment was performed $(\mathrm{pH}=7.4)$ using $\mathrm{HCl}$. An amoxicillin solution $(10 \mathrm{mg} / \mathrm{ml})$ was prepared using PBS at $\mathrm{pH}$ 7.4. Subsequently, $0.05 \mathrm{~g}$ of PCL microspheres were immersed in $5 \mathrm{ml}$ of amoxicillin solution at room temperature and kept for 24 hours. Then, particles were removed from PBS, and the drug concentration was measured using a UVVis spectrometer (Thermo-Scientific, Evolution 201) to determine drug adsorbed by the microspheres. Drug loaded microspheres were dried for 72 hours at room temperature prior to release experiments.

For the release experiments, drug-loaded PCL microspheres were immersed in test tubes containing $5 \mathrm{ml}$ PBS solution, and the drug concentration in the release medium at specified time intervals was measured using a UV-Vis spectrometer at $247 \mathrm{~nm}$. For the measurements, $2 \mathrm{ml}$ of PBS was withdrawn periodically and replaced with an equivalent volume of 
fresh buffer. 3 replicates were measured for each time, and results were averaged.

\section{Results and discussion}

In the study, the shape and surface state of the asprepared microspheres were analyzed using SEM. Morphology of the PCL microspheres prepared using dichloromethane at different stirring speeds is given in Figure 2. Spherical particles having a smooth surface was obtained when the stirring speed was $1500 \mathrm{rpm}$. However, a deviation from the spherical geometry and some surface roughness was observed at a lower stirring speed $(350 \mathrm{rpm})$. A significant difference was not observed in microsphere diameter depending on the applied stirring speed. The particle size of the PCL microspheres was measured to be $65.1 \pm 20$ and $59.8 \pm 23 \mu \mathrm{m}$ when the stirring speed was 350 and $1500 \mathrm{rpm}$, respectively (Table 1). It has been known that the stirring speed has a significant influence on the morphology of the polymeric particles fabricated by the emulsion-solvent evaporation

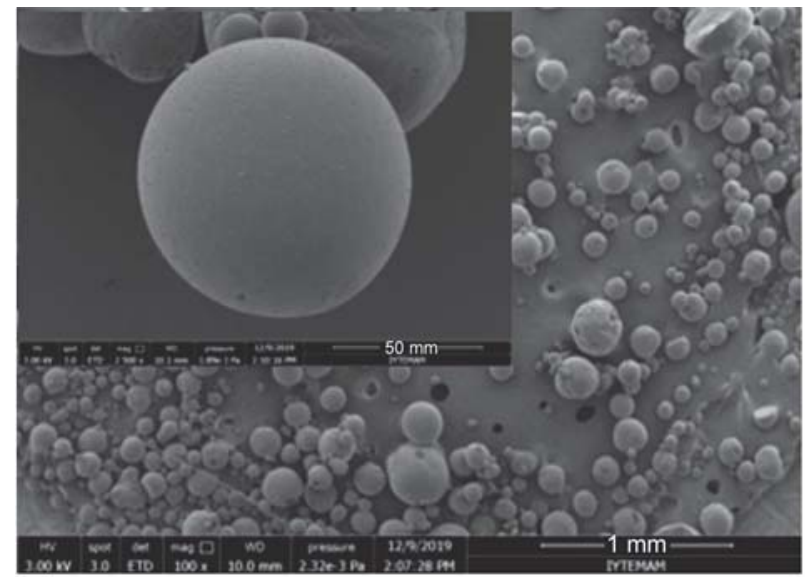

a)

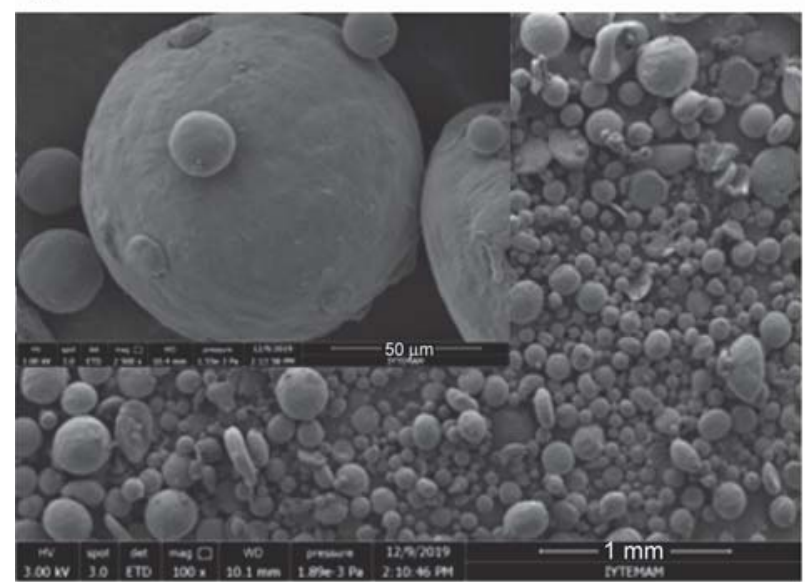

c)
Table 1. Effect of solvent type and graphene addition on the particle size of the PCL microspheres.

\begin{tabular}{|l|c|c|}
\hline \multirow{2}{*}{\multicolumn{1}{|c|}{ Sample code }} & \multicolumn{2}{|c|}{$\begin{array}{c}\text { Average particle size } \\
{[\boldsymbol{\mu m}]}\end{array}$} \\
\cline { 2 - 3 } & $\mathbf{3 5 0} \mathbf{~ r p m}$ & $\mathbf{1 5 0 0} \mathbf{~ r p m}$ \\
\hline PCL-DCM & $65.15 \pm 20.43$ & $59.81 \pm 23.09$ \\
\hline PCL-CHF & $19.44 \pm 5.24$ & $19.02 \pm 6.41$ \\
\hline PCL-DCM-G & - & $234.71 \pm 67.90$ \\
\hline PCL-CHF-G & - & $212.48 \pm 68.74$ \\
\hline
\end{tabular}

process [8]. When the stirring rate is higher, it causes the formation of finer dispersion of the microspheres [26]. The increase in stirring speed may also cause to formation of homogeneously distributed emulsion droplets, which is attributed to the stronger shear forces applied during the evaporation process [8]. In the current study, the increase of stirring speed presumably resulted in faster removal of dichloromethane from the system and the formation of spherical PCL microspheres with a smooth surface having smaller particle size. Based on this result, graphene

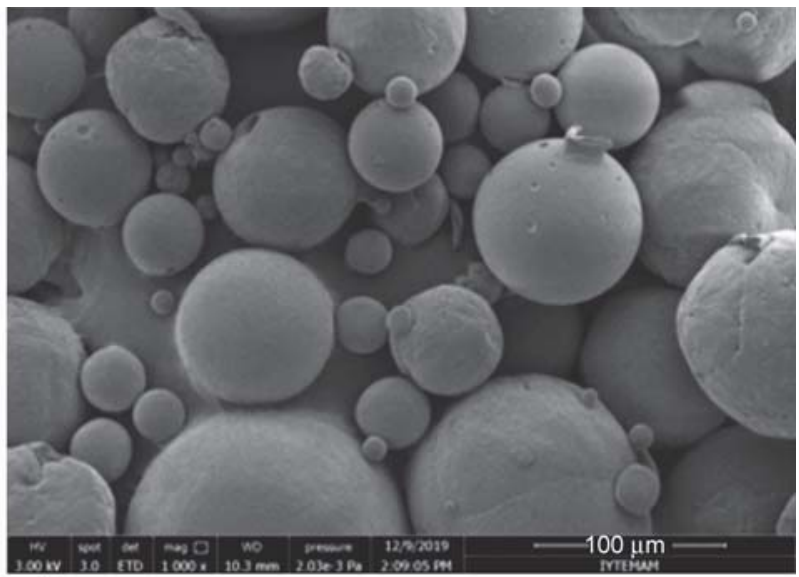

b)

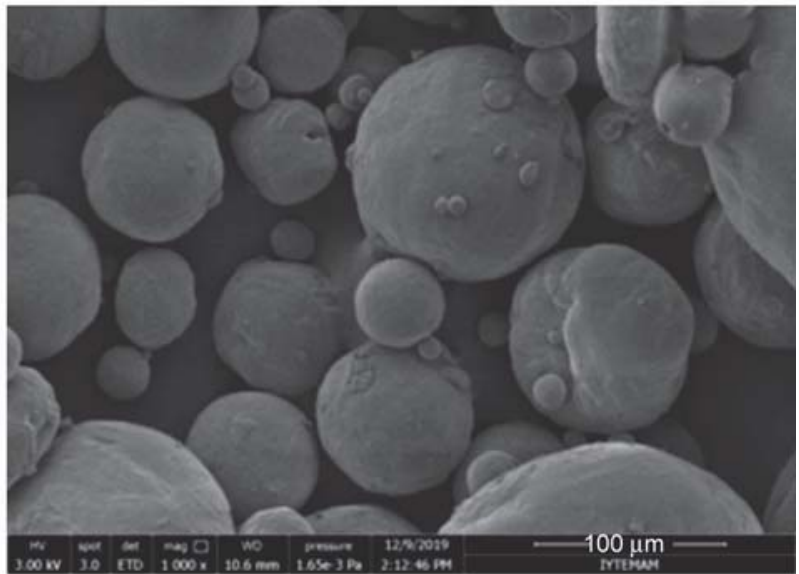

d)

Figure 2. SEM micrographs of the PCL-DCM microspheres prepared at different stirring speeds; (a), (b) $1500 \mathrm{rpm}$; (c), (d) $350 \mathrm{rpm}$. 
addition to the same system was only performed at a stirring speed of $1500 \mathrm{rpm}$.

Results also revealed that the inclusion of graphene nanopowders in the PCL system caused some changes in the morphology and size of the microspheres (Table 1). Figure 3 demonstrates the surface morphology of the graphene-containing PCL microspheres prepared by DCM. Accordingly, solid and few hollow PCL microsphere formations was seen in the presence of graphene nanopowders. Furthermore, an increase in surface porosity and microsphere diameter was observed. PCL particle diameter was measured to be $234.71 \pm 67.90 \mu \mathrm{m}$ in the presence of $1 \mathrm{wt} \%$ graphene. The increase obtained in particle size in the presence of graphene nanopowders is presumably due to the tendency of the spheres to aggregate and coalesce. It is also important to note that larger size polymeric microspheres have some advantages over smaller size particles in drug delivery applications. Pan et al. [9] reported the influence of particle size on the release of drugs from polymeric bio-adhesive

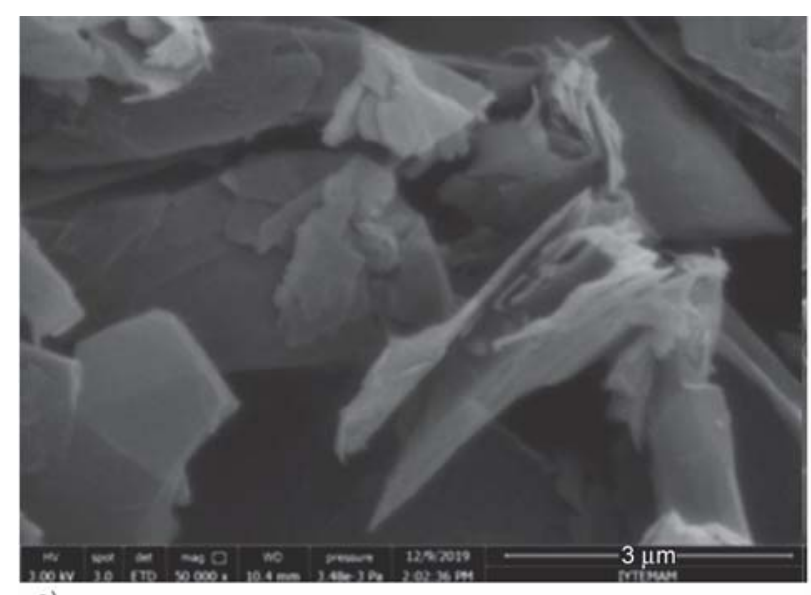

a)

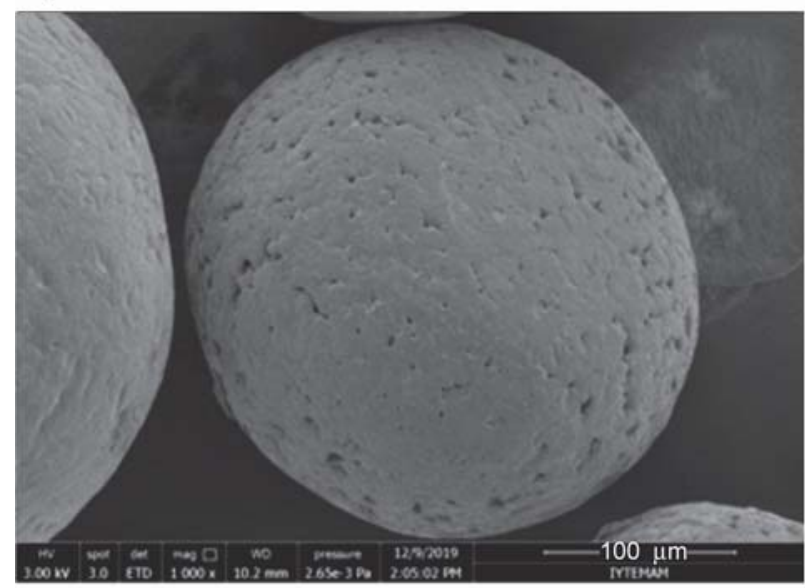

c) microspheres. It was shown that larger particles release less amount of insulin at the initial burst stage and preventing initial burst [9]. Berkland et al. [27] have been demonstrated that the drug release behavior of microspheres strongly depends on the microsphere diameter. It has been reported that in the range of 10 to $20 \mu \mathrm{m}$ particles exhibit concave-downward release profiles while larger particles result in sigmoidal release profiles [27]. Therefore, the larger size of the graphene- PCL composite microspheres prepared in the current study may have an advantage over bare PCL microspheres in local drug delivery applications.

In the study, the second solvent tested in the preparation of the oil phase was the chloroform. Figure 4 shows the SEM micrographs of the PCL microspheres produced using chloroform at different stirring speeds. Results showed that a significant difference was not obtained in PCL microsphere morphology and size depending on the stirring speed (Table 1). However, compared to the PCL microspheres prepared using

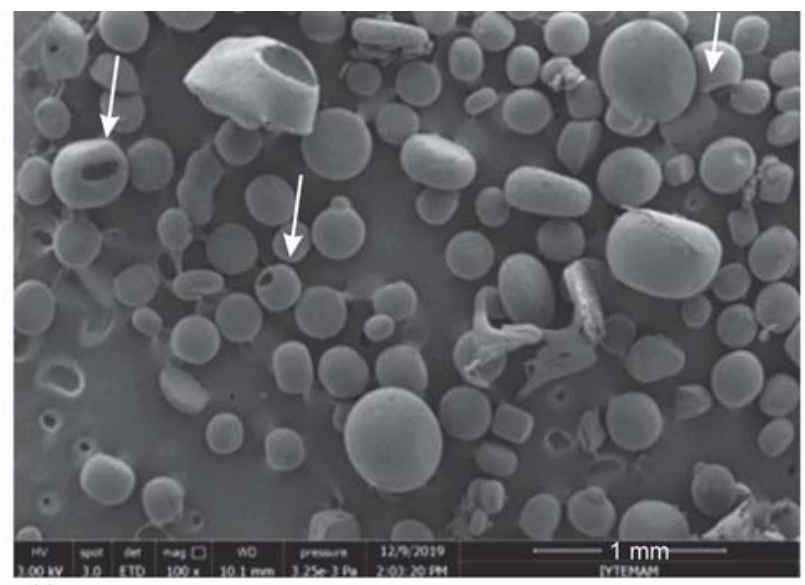

b)

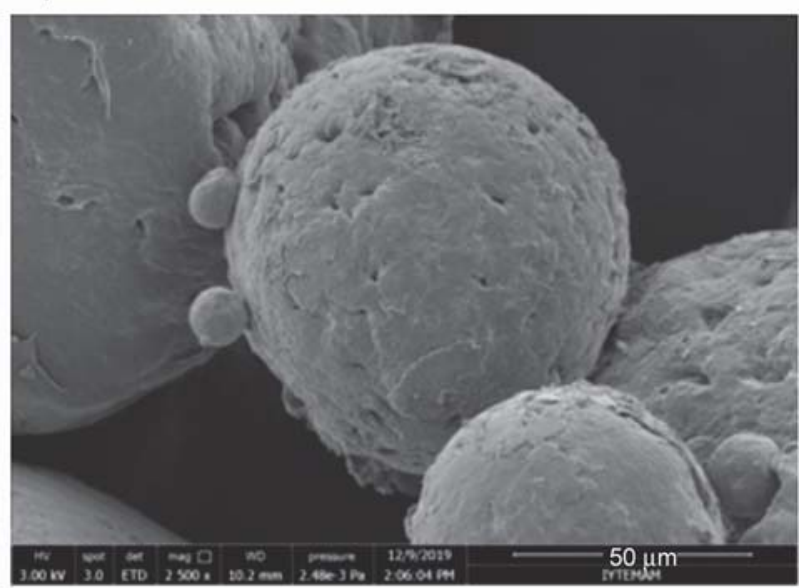

d)

Figure 3. SEM micrographs of the (a) as-received graphene nanoplatelets, (b), (c), (d) PCL-DCM-G microspheres prepared @ $1500 \mathrm{rpm}$. White solid arrows indicate the hollow microspheres. 


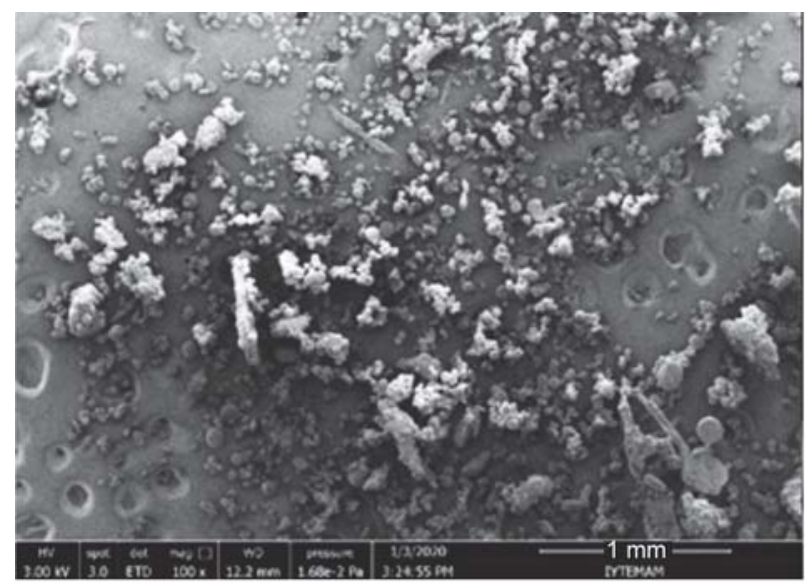

a)

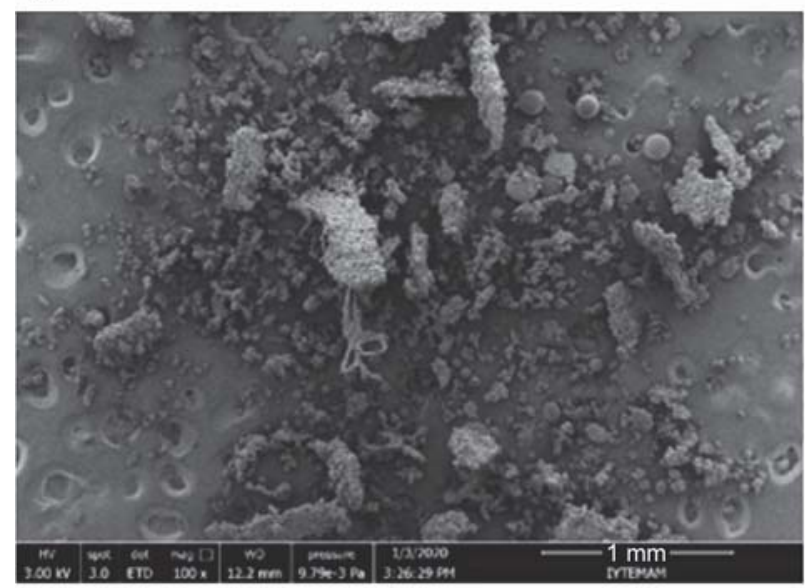

c)

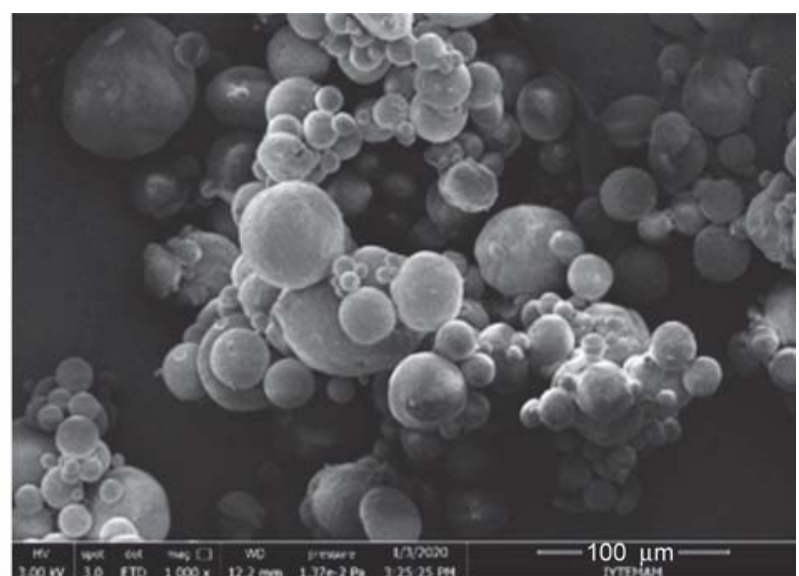

b)

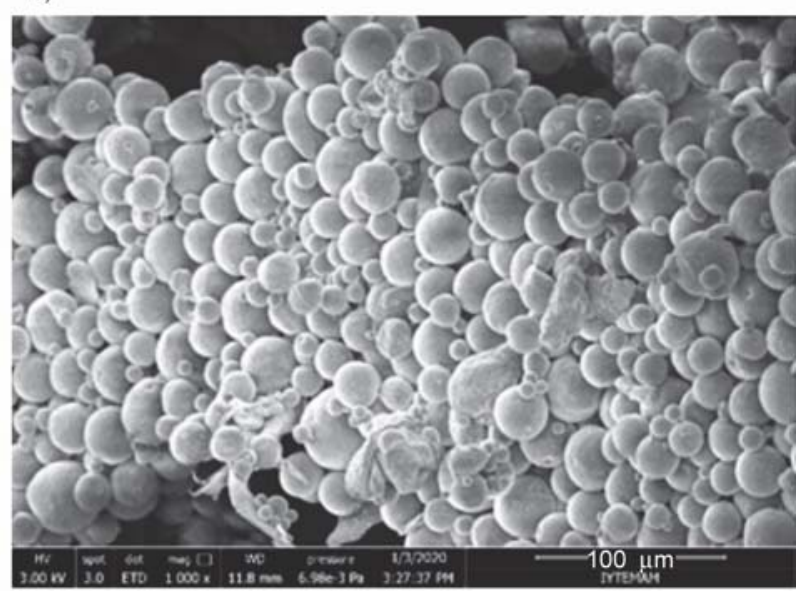

d)

Figure 4. SEM micrographs of the PCL-CHF microspheres prepared at different stirring speeds; (a), (b) $350 \mathrm{rpm}$; (c), (d) $1500 \mathrm{rpm}$.

dichloromethane, a smaller particle size $(\sim 19 \mu \mathrm{m})$ was obtained when chloroform was utilized. The mean particle size of the PCL microspheres $(\sim 20 \mu \mathrm{m})$ was found within the injectable range [28].

Similarly, addition of graphene nanopowders to the PCL matrix caused an increase in particle diameter by almost tenfold. But more importantly, the presence

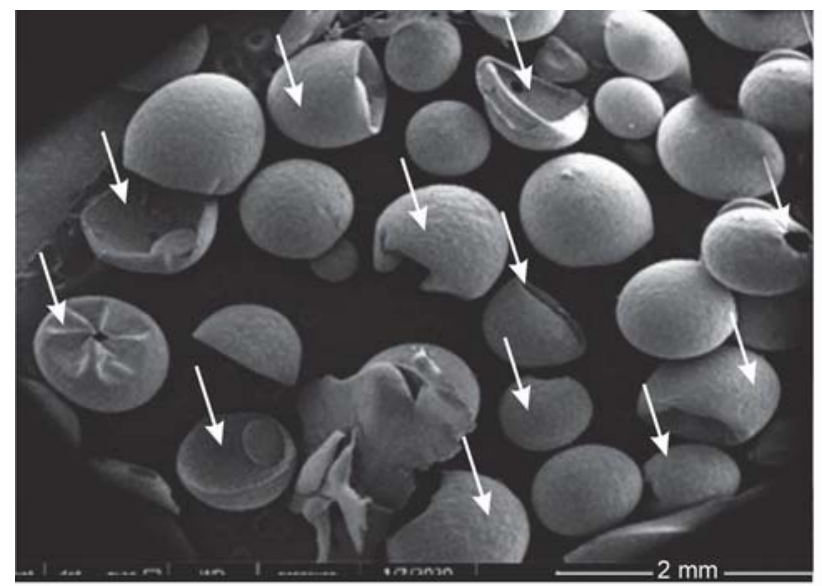

a) of graphene nanopowders in the chloroform-PCL oil phase led to the formation of hollow PCL microspheres, as shown in Figure 5. Besides, particle size distribution was narrower and more homogenous compared to the PCL microspheres prepared by DCM (Figure 6). A significant difference was not observed in particle size as a function of stirring speed similar

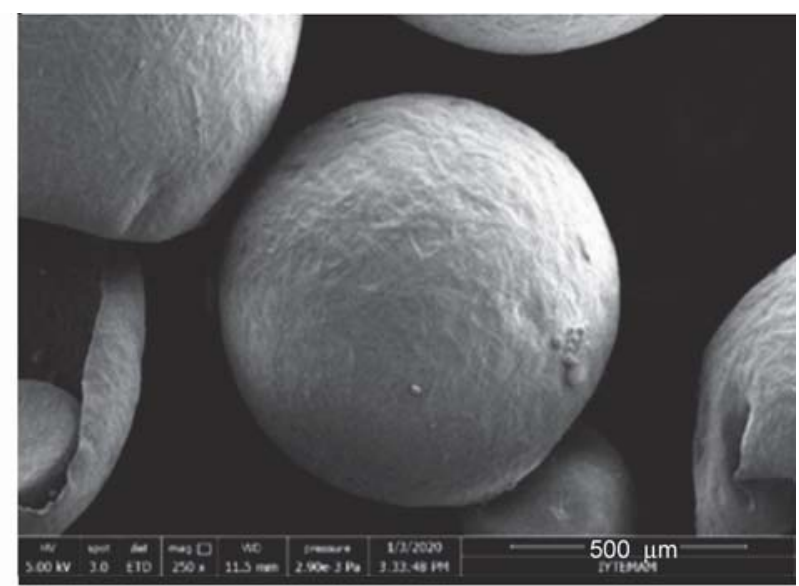

b)

Figure 5. SEM micrographs of the PCL-CHF-G microspheres (a), (b) (@1500 rpm). White solid arrows indicate the hollow microspheres. 

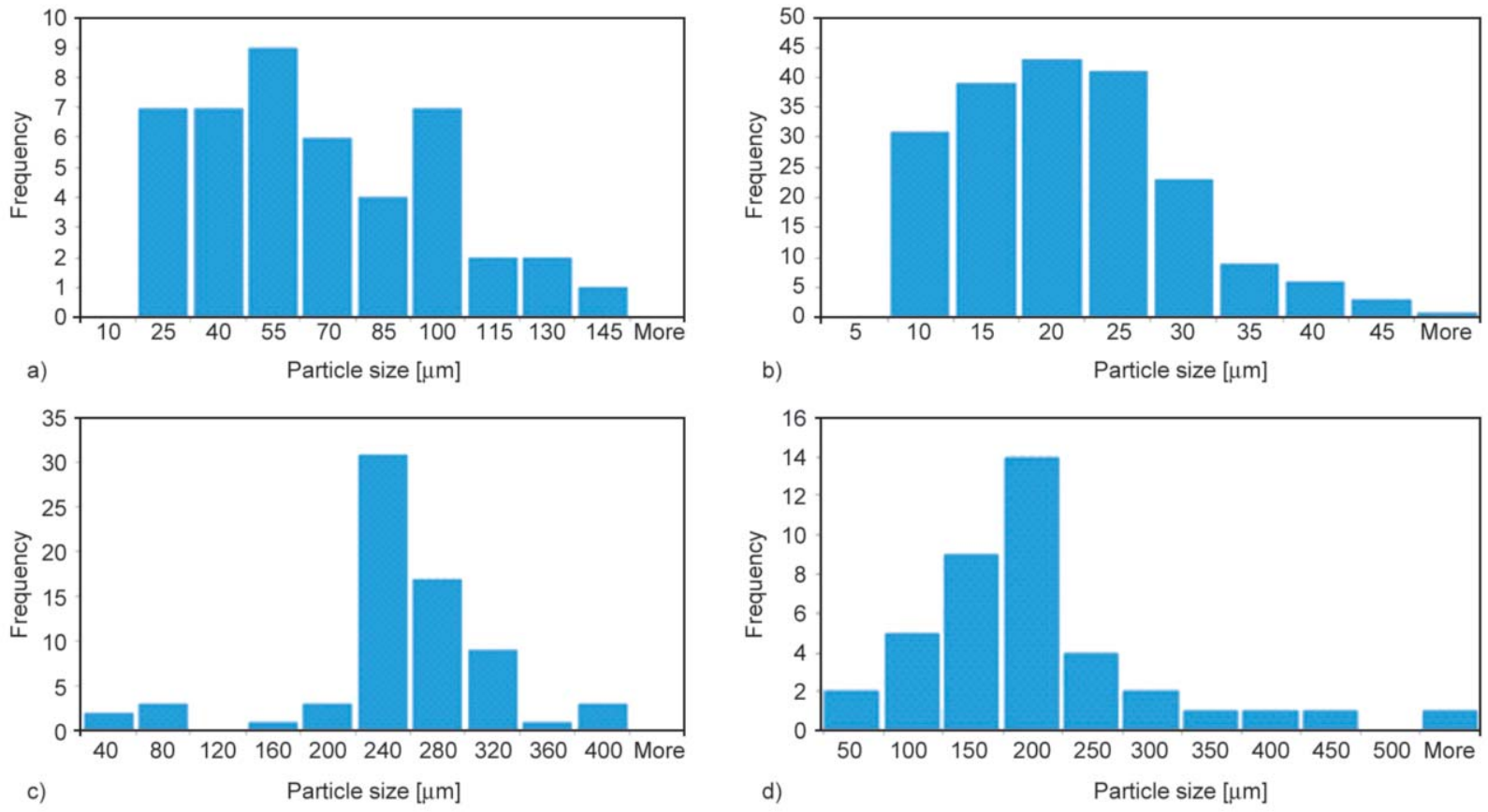

Figure 6. Particle size distribution of (a) PCL-DCM, (b) PCL-CHF, (c) PCL-DCM-G, (d) PCL-CHF-G microspheres prepared at the same stirring speed (@1500 rpm).

to microspheres prepared using dichloromethane since both dichloromethane and chloroform are good solvents for PCL [29].

A previous study conducted by Carreras et al. [30] showed that using $\mathrm{o}_{1} / \mathrm{o}_{2} / \mathrm{w}$ double emulsion method and DCM as the solvent PCL microspheres having a wide particle size distribution with an average particle size of $846.9 \pm 64.95 \mathrm{~nm}$ can be obtained [28]. Similarly, in the past study of Luciani et al. [31] PCL microspheres produced by the single emulsion method. Results indicated the existence of spherical, non-porous surface structure with a particle size range of 100 to $800 \mu \mathrm{m}$. Dhanka et al. [32] reported that the PCL microspheres had been fabricated by o/w single emulsion-solvent evaporation method using hydroxypropyl methylcellulose as the emulsifier and dichloromethane as the solvent. The mean size of microspheres was found to be $23 \mu \mathrm{m}$ that is within the injectability criteria. Karamzadeh et al. [33] described the preparation of methadone hydrochlorideloaded PCL microspheres by (w/o/w) double emulsion solvent evaporation method using DCM. Synthesized PCL microspheres indicated a spherical morphology with a smooth surface, and their sizes were in the range of 4.5-20 $\mu \mathrm{m}$ [33]. Among other solvents, Das et al. [8] investigated the synthesis of PCL microspheres using chloroform as the solvent and the polyvinyl polyline as the emulsifier. The PCL particles demonstrated a spherical shape with a size in the range of 5 to $20 \mu \mathrm{m}$. Similarly, Manoukian et al. [34] reported the preparation of biodegradable PCL injectable microspheres $(300 \pm 125 \mu \mathrm{m})$ and implants for long-term delivery of drugs by o/w emulsion-solvent evaporation method using chloroform as the solvent.

Based on these studies, it is possible to conclude that both dichloromethane and chloroform can be used as the solvents in the preparation of PCL microspheres. The evaporation temperatures of chloroform and dichloromethane are 61 and $39^{\circ} \mathrm{C}$, respectively. Therefore, microspheres form faster when using dichloromethane [24]. This may influence both the morphological features and the particle size of the prepared microspheres [35]. Another critical factor determining the particle size and morphology of the microspheres may be the distance between the solvent and the polymer molecules. It also affects the compatibility as well as interactions between them. A small distance indicates compatibility and strong interactions between solvent and polymer. The distance between PCL-chloroform and PCL-dichloromethane is 1.9 and 3.7, respectively $[29,36]$. Therefore, in the current study, smaller particle size of PCL microspheres when the chloroform was used may be attributed to the solubility characteristics of PCL in this solvent.

In the study, the formation of hollow PCL microspheres in the presence of graphene nanopowders 


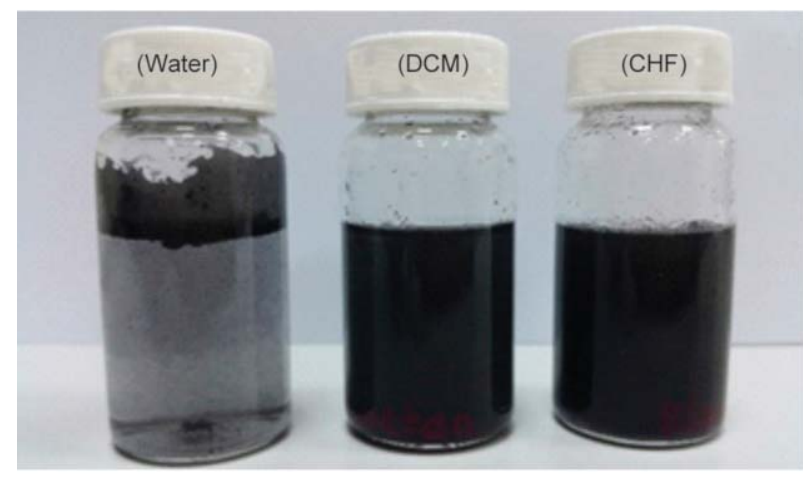

a)

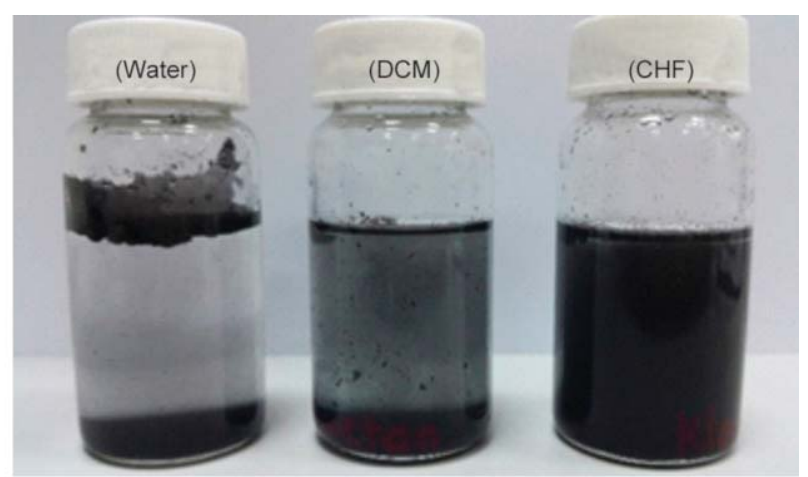

b)

Figure 7. Digital images showing the dispersion state of graphene nanopowders ( $1 \mathrm{wt} \%)$ in different solvents used in the study (a) initially, (b) after 30 minutes.

may be attributed to the Ostwald ripening, which is the growth of larger particles at the expense of smaller particles [37, 38]. Based on this approach, a PCL particle was presumably precipitated on the smaller size graphene nanoplatelets in the initial step, which is followed by the close interaction and aggregation of the graphene nanoparticles through Van der Waals forces. The critical issue in this mechanism is the existence of highly hydrophobic nanoparticles, which may cause a phase separation when they are dispersed in a water-based medium (Figure 7). Besides, the use of a polymer solution at low concentrations may be another factor for the hollow polymeric microsphere formation. Preparation of graphene-PCL hollow microspheres using this approach has not been reported previously. The formation of hollow geometry and the presence of graphene nanoflakes on the surface of the PCL may enhance the adsorption capabilities of the microspheres due to an increase in surface area. In addition to the larger particle size of the graphenePCL composite microspheres prepared in the current study, the existence of a hollow geometry is beneficial for drug loading and sustained release applications. Jang et al. [17] fabricated hollow PCL microspheres with a porous surface morphology using solvent/ non-solvent emulsion technique. In the study, different morphologies were modulated by changing the PCL concentration. Huo et al. [39] prepared hollow ferrocenyl coordination polymer microspheres having micropores in the shells by Ostwald ripening approach. It was reported that the formation of hollow microspheres is due to the mass transfer and also crystallization of small crystallites through the Ostwald ripening process [39]. Figure 8 depicts the possible pathway of the hollow microsphere formation mechanism proposed in the current study.

FT-IR spectrum of the as-received PCL, graphene nanopowders, and the solvents utilized in the study is shown in Figure 9. Pure PCL demonstrates characteristic peaks at $1725 \mathrm{~cm}^{-1}$ and also at 2865$2948 \mathrm{~cm}^{-1}$, as well as the $\mathrm{C}-\mathrm{O}-\mathrm{C}$ stretching vibrations peaks at $1163-1247 \mathrm{~cm}^{-1}$. On the other hand, FTIR spectrum of liquid chloroform shows the $\mathrm{C}-\mathrm{H}$ stretching $\left(v_{1}\right)$ mode at $3019 \mathrm{~cm}^{-1}$, the $\mathrm{C}-\mathrm{H}$ bending $\left(v_{4}\right)$ at $1215 \mathrm{~cm}^{-1}, \mathrm{C}-\mathrm{Cl}_{3}$ stretching $\left(v_{2}\right)$ at 680 and $775 \mathrm{~cm}^{-1}\left(v_{5}\right)$ [40]. Similarly, spectrum of the liquid dichloromethane demonstrates same functional groups at 700, 731 and $1264 \mathrm{~cm}^{-1}$ [41].

Figure 10 depicts the FTIR spectra of the bare and composite PCL microspheres prepared in the study. The peak at $1725 \mathrm{~cm}^{-1}$ is due to the $\mathrm{C}=\mathrm{O}$ stretching vibration of PCL microspheres. The $\mathrm{C}-\mathrm{O}-\mathrm{C}$ stretching of PCL microspheres is shown at $1163-1247 \mathrm{~cm}^{-1}$ and $\mathrm{CH}$ stretching vibrations at $2865-2948 \mathrm{~cm}^{-1}[42$, 43]. The spectra of the microspheres did not contain the functional groups of the solvents, indicating their

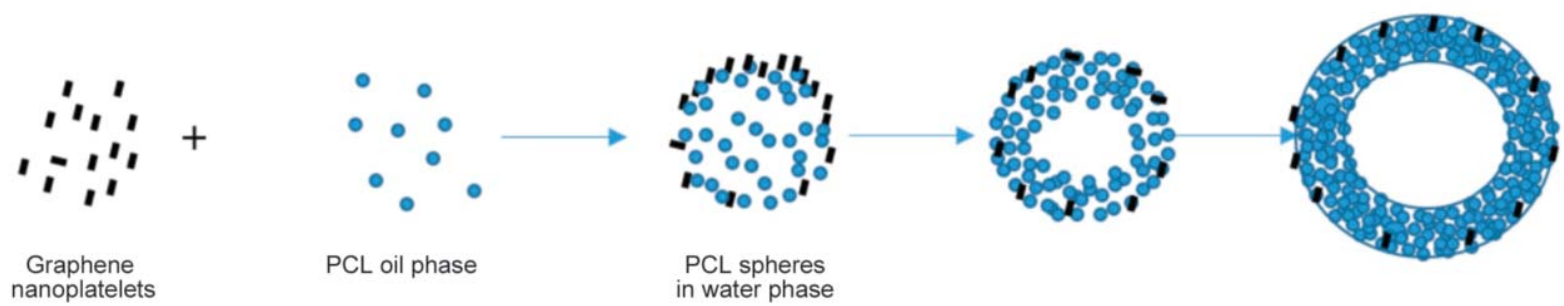

Figure 8. Schematic illustration of the PCL hollow microsphere formation in the presence of graphene nanopowders. 

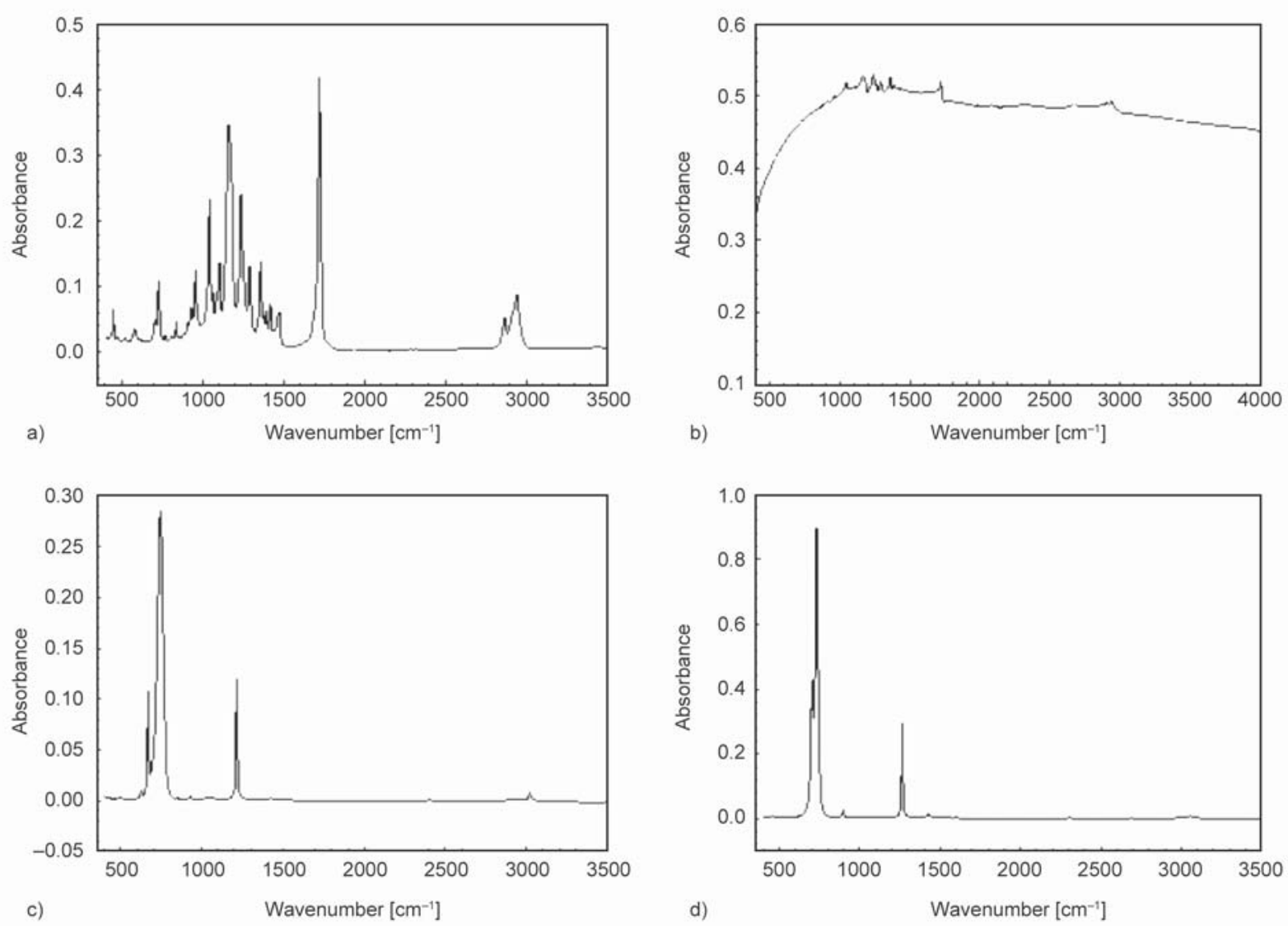

Figure 9. FTIR spectra of the as-received (a) PCL, (b) graphene, (c) chloroform, (d) dichloromethane, used in the study.

complete removal from the structure through evaporation. Additionally, a difference was not observed in the spectrum of PCL microspheres prepared using chloroform or dichloromethane in terms of peak position. Absorbance values were higher in the case of PCL-CHF microspheres compared to the PCL-DCM, which is presumably due to the solubility characteristics of PCL in these solvents. Intrinsic viscosity [ $\eta]$ of PCL in chloroform and dichloromethane is 0.420 and $0.342 \mathrm{dl} / \mathrm{g}$, respectively [44]. It has been known that $[\eta]$ decreases with decreasing solvent-solute affinity. Therefore, PCL has a higher affinity to chloroform compared to dichloromethane.

Similarly, the presence of graphene nanoflakes did not cause a difference in the peak position of the spectrum of PCL since graphene has few functional groups, as shown in Figure 9b. Pristine graphene generally shows a low-intensity band at $955 \mathrm{~cm}^{-1}$ that can be ascribed to the $\mathrm{C}-\mathrm{O}$ stretching vibrations of the carboxyl groups [45]. However, the inclusion of graphene to the PCL microsphere structure caused a decrease in the absorbance values.

In the FTIR spectrum, an increase in the peak intensity usually refers to an increase in the concentration of the functional group associated with the molecular bond, whereas a shift in peak position refers to the hybridization state or the change in electron distribution in the molecular bond [46]. Therefore, in Figure 10, the decrease observed in absorbance values of the PCL microspheres prepared by dichloromethane and PCL-graphene composite microspheres may be attributed to the decrease in PCL concentration within these samples.

In the study, drug release experiments were performed using amoxicillin, which is a $\beta$-lactam antibiotic used to treat a number of bacterial infections [47]. Drug loading studies showed that after 24 hours of immersion, the adsorption percentages of the drug were 65 and $37 \%$ for the composite hollow and bare solid PCL microspheres, respectively. Both hollow morphology and larger size as well as the presence of graphene nanopowders may be the reasons for the enhanced adsorption for the composite microspheres. Figure 11 demonstrates the cumulative amoxicillin release percentages of the bare solid PCL and graphene-PCL composite hollow microspheres prepared in the study. Based on the release graph PCL solid microspheres showed burst release during the 

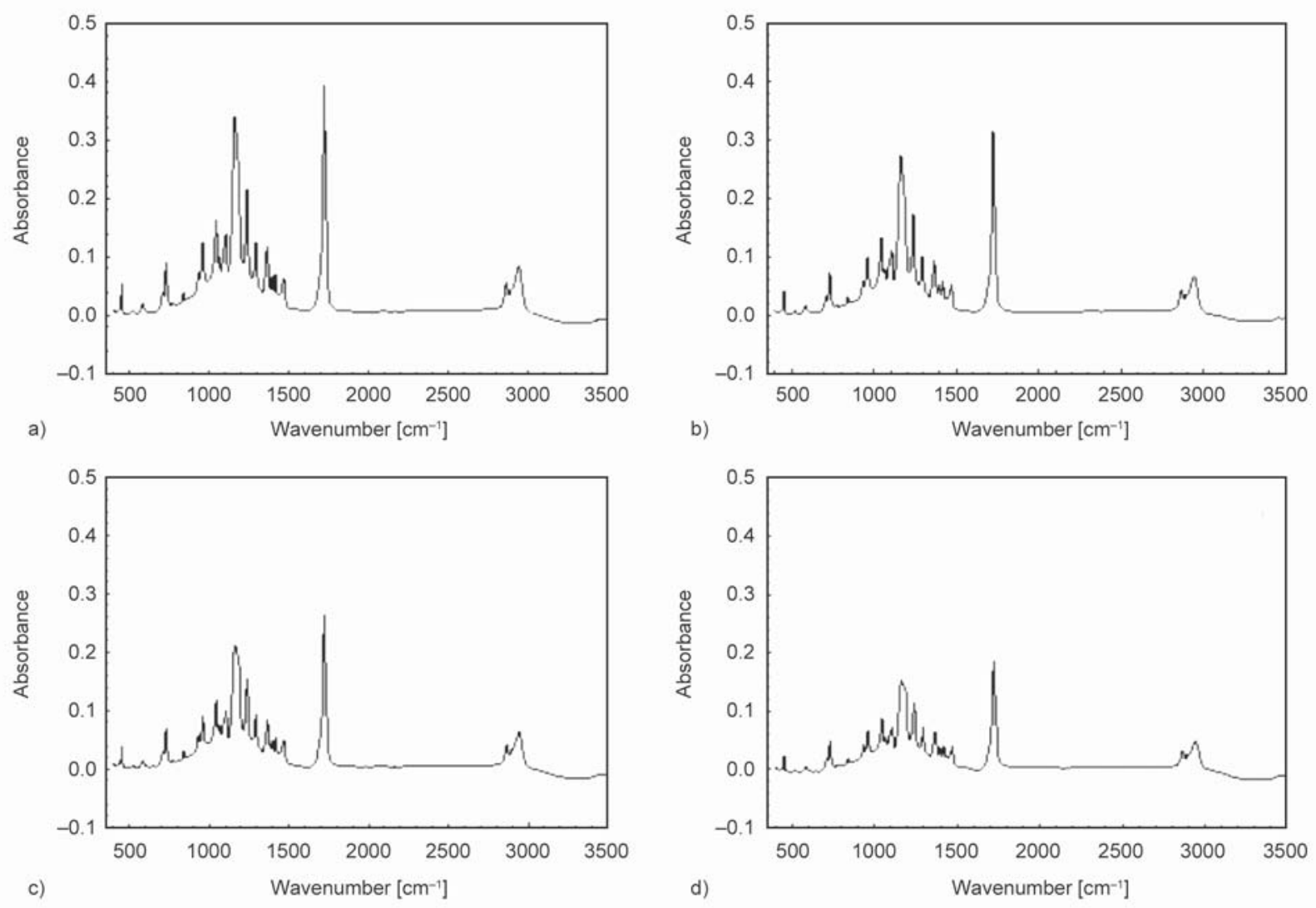

Figure 10. FTIR spectra of the (a) PCL-CHF, (b) PCL-CHF-G, (c) PCL-DCM, (d) PCL-CHF-G microspheres prepared (@1500 rpm) in the study.

first 24 hours (almost 52\%) compared to PCLgraphene hollow microspheres (34.6\%); thereafter, amoxicillin release continued at a reduced rate for the solid microspheres. In the case of PCL-graphene hollow microspheres, there was an acceleration of the drug release in the second period, which reached $83 \%$ after 168 hours. It can be concluded that the hollow microspheres release amoxicillin in a more controlled manner due to their high surface area and presence of graphene in the structure.

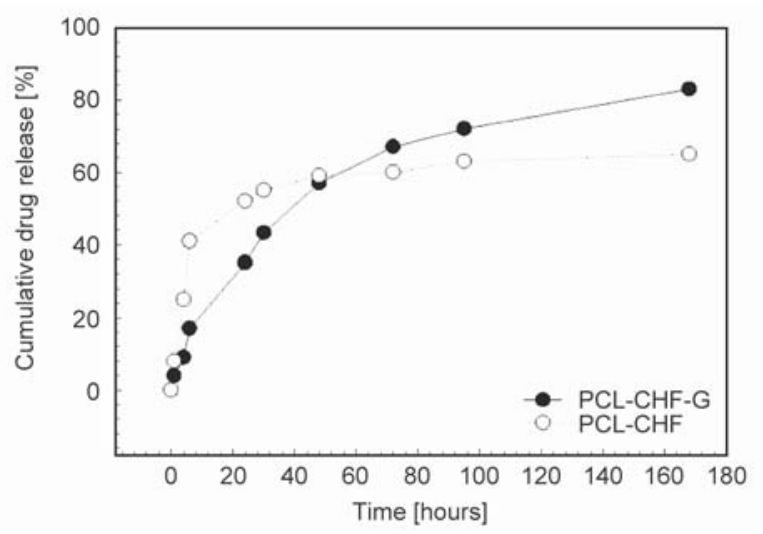

Figure 11. Graph showing the amoxicillin release from the bare PCL solid and graphene-containing hollow microspheres.

\section{Conclusions}

In the study, solid and hollow PCL microspheres were prepared by the o/w emulsion solvent evaporation method using different solvents and graphene nanopowders. Results showed that solvents utilized in the study strongly affected the surface state and size of the PCL microspheres. When the dichloromethane was used as the solvent, the average size of the particles was in the range of 60 to $65 \mu \mathrm{m}$. On the other hand, when chloroform was utilized it was possible to obtain solid microspheres having a smooth surface with an average particle size of $\sim 19 \mu \mathrm{m}$. The change in the stirring speed did not significantly influence the particle size of the microspheres. The introduction of graphene nanopowders to the same system caused the formation of hollow PCL microspheres with a much larger particle size $(\sim 200 \mu \mathrm{m})$. The formation mechanism of the PCL hollow microspheres in the presence of graphene nanopowders could be attributed to the Ostwald ripening process. Results also showed that the formation of hollow geometry and the larger size of the PCL-graphene composite microspheres was beneficial in amoxicillin release in PBS since larger particle size and 
presence of graphene prevented the burst release of the drug. The microspheres fabricated in the study may find applications in local delivery of drugs and proteins as well as in scaffold manufacture for tissue engineering purposes.

\section{Acknowledgements}

SEM analysis was performed at Izmir Institute of Technology, Materials Research Center.

\section{References}

[1] Saralidze K., Koole L. H., Knetsch M. L. W.: Polymeric microspheres for medical applications. Materials, 3, 3537-3564 (2010). https://doi.org/10.3390/ma3063537

[2] Bao W., Zhou J., Luo J., Wu D.: PLGA microspheres with high drug loading and high encapsulation efficiency prepared by a novel solvent evaporation technique. Journal of Microencapsulation, 23, 471-479 (2006). https://doi.org/10.1080/02652040600687613

[3] Kemala T., Budianto E., Soegiyono B.: Preparation and characterization of microspheres based on blend of poly(lactic acid) and poly( $\varepsilon$-caprolactone) with poly (vinyl alcohol) as emulsifier. Arabian Journal of Chemistry, 5, 103-108 (2012).

https://doi.org/10.1016/j.arabjc.2010.08.003

[4] Rizkalla N., Range C., Lacasse F-X., Hildgen P.: Effect of various formulation parameters on the properties of polymeric nanoparticles prepared by multiple emulsion method. Journal of Microencapsulation, 23, 39-57 (2006). https://doi.org/10.1080/02652040500286185

[5] Blanco M. D., Sastre R. L., Teijón C., Olmo R., Teijon J. M.: 5-Fluorouracil-loaded microspheres prepared by spray-drying poly(D,L-lactide) and poly(lactide-co-glycolide) polymers: Characterization and drug release. Journal of Microencapsulation, 22, 671-682 (2005). https://doi.org/10.1080/02652040500161990

[6] Natarajan V., Krithica N., Madhan B., Sehgal P. K.: Formulation and evaluation of quercetin polycaprolactone microspheres for the treatment of rheumatoid arthritis. Journal of Pharmaceutical Sciences, 100, 195-205 (2011). https://doi.org/10.1002/jps.22266

[7] Sinha V. R., Bansal K., Kaushik R., Kumria R., Trehan A.: Poly- $\varepsilon$-caprolactone microspheres and nanospheres: An overview. International Journal of Pharmaceutics, 278, 1-23 (2004). https://doi.org/10.1016/j.ijpharm.2004.01.044

[8] Das P. P., Huda M. K., Saikia P. J., Baruah S. D.: Study of the formation of biodegradable polycaprolactone particles using solvent evaporation method. Journal of Macromolecular Science Part A, 56, 69-75 (2019). https://doi.org/10.1080/10601325.2018.1547112
[9] Pan Y., Zheng J-M., Zhao H-Y., Li Y-J., Xu H., Wei G.: Relationship between drug effects and particle size of insulin-loaded bio-adhesive microspheres. Acta Pharmacologica Sinica, 23, 1051-1056 (2002).

[10] Kim M-J., Koh Y-H.: Synthesis of aligned porous poly ( $\varepsilon$-caprolactone) (PCL)/hydroxyapatite (HA) composite microspheres. Materials Science and Engineering C: Materials for Biological Applications, 33, 2266-2272 (2013). https://doi.org/10.1016/j.msec.2013.01.051

[11] Shin S-W., Jang Y-D., Ko K-W., Kang E. Y., Han J-H., Bedair T. M., Kim I-H., Son T-I., Park W., Han D. K.: PCL microspheres containing magnesium hydroxide for dermal filler with enhanced physicochemical and biological performances. Journal of Industrial and Engineering Chemistry, 80, 854-861 (2019). https://doi.org/10.1016/j.jiec.2019.07.043

[12] Wang P., Zhang T., Tong X., Liu L., Wang G.: A method for preparation $\mathrm{PCL} / \mathrm{CoFe}_{2} \mathrm{O}_{4}$ magnetic composite microspheres and the properties. Journal of Physics: Conference Series, 1087, 052005/1-052005/7 (2018). https://doi.org/10.1088/1742-6596/1087/5/052005

[13] Ramli R. A.: Hollow polymer particles: A review. RSC Advances, 7, 52632-52650 (2017).

https://doi.org/10.1039/c7ra10358a

[14] Kang X., Yang D., Ma P., Dai Y., Shang M., Geng D., Cheng Z., Lin J.: Fabrication of hollow and porous structured $\mathrm{GdVO}_{4}: \mathrm{Dy}^{3+}$ nanospheres as anticancer drug carrier and MRI contrast agent. Langmuir, 29, 12861294 (2013). https://doi.org/10.1021/la304551y

[15] Mangeney C., Bousalem S., Connan C., Vaulay M-J., Bernard S., Chehimi M. M.: Latex and hollow particles of reactive polypyrrole: Preparation, properties, and decoration by gold nanospheres. Langmuir, 22, 1016310169 (2006). https://doi.org/10.1021/la060910f

[16] Zhou F-L., Chirazi A., Gough J. E., Cristinacce P. L. H., Parker G. J. M.: Hollow polycaprolactone microspheres with/without a single surface hole by co-electrospraying. Langmuir, 33, 13262-13271 (2017). https://doi.org/10.1021/acs.langmuir.7b01985

[17] Jang T-S., Lee E-J., Kim H-E., Koh Y-H.: Hollow porous poly( $\varepsilon$-caprolactone) microspheres by emulsion solvent extraction. Materials Letters, 72, 157-159 (2012).

https://doi.org/10.1016/j.matlet.2011.12.105

[18] Neto A. C., Guinea F., Peres N. M. R.: Drawing conclusions from graphene. Physics World, 19, 33-37 (2006). https://doi.org/10.1088/2058-7058/19/11/34

[19] Kumar D., Babu G., Krishnan S.: Study on mechanical $\&$ thermal properties of PCL blended graphene biocomposites. Polímeros, 29, e2019024/1-e2019024/9 (2019). https://doi.org/10.1590/0104-1428.05318

[20] Shen H., Zhang L., Liu M., Zhang Z.: Biomedical applications of graphene. Theranostics, 2, 283-294 (2012). https://doi.org/10.7150/thno.3642 
[21] Deliormanl1 M. A.: Direct write assembly of graphene/ poly( $\varepsilon$-caprolactone) composite scaffolds and evaluation of their biological performance using mouse bone marrow mesenchymal stem cells. Journal of Applied Biochemistry and Biotechnology, 188, 1117-1133 (2019).

https://doi.org/10.1007/s12010-019-02976-5

[22] Deliormanlı M. A., Atmaca H.: Prechondrogenic ATDC5 cell response to graphene/multi-walled carbon nanotube-containing porous polycaprolactone biocomposite scaffolds. Journal of Polymeric Materials and Polymeric Biomaterials, 68, 1154-1166 (2019).

https://doi.org/10.1080/00914037.2018.1539984

[23] Deliormanlı M. A., Atmaca H.: Effect of pore architecture on the mesenchymal stem cell responses to graphene/polycaprolactone scaffolds prepared by solvent casting and robocasting. Journal of Porous Materials, 27, 49-61 (2020). https://doi.org/10.1007/s10934-019-00791-1

[24] Bile J., Bolzinger M-A., Vigne C., Boyron O., Valour J-P., Fessi H., Chevalier Y.: The parameters influencing the morphology of poly( $\varepsilon$-caprolactone) microspheres and the resulting release of encapsulated drugs. International Journal of Pharmaceutics, 494, 152-166 (2015). https://doi.org/10.1016/j.ijpharm.2015.07.068

[25] Bolourtchian N., Karimi K., Aboofazeli R.: Preparation and characterization of ibuprofen microspheres. Journal of Microencapsulation, 22, 529-538 (2005). https://doi.org/10.1080/02652040500161941

[26] Mateovic T., Kriznar B., Bogataj M., Mrhar A.: The influence of stirring rate on biopharmaceutical properties of Eudragit RS microspheres. Journal of Microencapsulation, 19, 29-36 (2002).

https://doi.org/10.1080/02652040010055289

[27] Berkland C., King M., Cox A., Kim K., Pack D. W.: Precise control of PLG microsphere size provides enhanced control of drug release rate. Journal of Control Release, 82, 137-147 (2002).

https://doi.org/10.1016/S0168-3659(02)00136-0

[28] Campos E., Branquinho J., Carreira A. S., Carvalho A., Coimbra P., Ferreira P., Gil M. H.: Designing polymeric microparticles for biomedical and industrial applications. European Polymer Journal, 49, 2005-2021 (2016). https://doi.org/10.1016/j.eurpolymj.2013.04.033

[29] Zhang S., Campagne C., Salaün F.: Influence of solvent selection in the electrospraying process of polycaprolactone. Applied Sciences, 9, 402/1-402/36 (2019). https://doi.org/10.3390/app9030402

[30] Carreras N., Acuña V., Martí M., Lis M. J.: Drug release system of ibuprofen in PCL-microspheres. Colloid and Polymer Science, 291, 157-165 (2013). https://doi.org/10.1007/s00396-012-2768-x

[31] Luciani A., Coccoli V., Orsi S., Ambrosio L., Netti P. A.: PCL microspheres based functional scaffolds by bottom-up approach with predefined microstructural properties and release profiles. Biomaterials, 29, 4800 4807 (2008).

https://doi.org/10.1016/j.biomaterials.2008.09.007
[32] Dhanka M., Shetty C., Srivastava R.: Injectable methotrexate loaded polycaprolactone microspheres: Physicochemical characterization, biocompatibility, and hemocompatibility evaluation. Materials Science and Engineering C: Materials for Biological Applications, 81, 542-550 (2017).

https://doi.org/10.1016/j.msec.2017.08.055

[33] Karamzadeh Y., Asl A. A., Rahmani S.: PCL microsphere/PEG-based composite hydrogels for sustained release of methadone hydrochloride. Applied Polymer Science, 137, 48967/1-48967/11 (2020). https://doi.org/10.1002/APP.48967

[34] Manoukian O. S., Arul M. R., Sardashti N., Stedman T., James R., Rudraiah S., Kumbar S. G.: Biodegradable polymeric injectable implants for long-term delivery of contraceptive drugs. Journal of Applied Polymer Science, 135, 46068/1-46068/9 (2018). https://doi.org/10.1002/app.46068

[35] Subedi G., Shrestha A. K., Shakya S.: Study of effect of different factors in formulation of micro and nanospheres with solvent evaporation technique. Open Pharmaceutical Sciences Journal, 3, 182-195 (2016). https://doi.org/10.2174/1874844901603010182

[36] Gao J., Wu S., Rogers M. A.: Harnessing Hansen solubility parameters to predict organogel formation. Journal of Materials Chemistry, 22, 12651-12658 (2012). https://doi.org/10.1039/C2JM32056H

[37] Wang W-S., Zhen L., Xu C-Y., Shao W-Z.: Aqueous solution synthesis of $\mathrm{Cd}(\mathrm{OH})_{2}$ hollow microspheres via Ostwald ripening and their conversion to $\mathrm{CdO}$ hollow microspheres. Journal of Physical Chemistry, 112, 14360-14366 (2008). https://doi.org/10.1021/jp8046483

[38] Tadros T.: Ostwald ripening. in 'Encyclopaedia of colloid and interface science' (ed.: Tadros T.) Springer, Berlin, Heidelberg, 820-821 (2013). https://doi.org/10.1007/978-3-642-20665-8_124

[39] Huo J., Wang L., Irran E., Yu H., Gao J., Fan D., Li B., Wang J., Ding W., Amin A. M., Li C., Ma L.: Hollow ferrocenyl coordination polymer microspheres with micropores in shells prepared by Ostwald ripening. Angewandte Chemie International Edition, 49, 9237-9241 (2010). https://doi.org/10.1002/anie.201004745

[40] Nishida J., Shigeto S., Yabumoto S., Hamaguchi H.: Anharmonic coupling of the $\mathrm{CH}$-stretch and $\mathrm{CH}$-bend vibrations of chloroform as studied by near-infrared electroabsorption spectroscopy. The Journal of Chemical Physics, 137, 234501/1-234501/9 (2012). https://doi.org/10.1063/1.4770264

[41] Abd Allah Z., Sawtell D., Kasyutich V. L., Martin P. A.: FTIR and QCL diagnostics of the decomposition of volatile organic compounds in an atmospheric pressure dielectric packed bed plasma reactor. Journal of Physics: Conference Series, 157, 012001/1-012001/9 (2009). https://doi.org/10.1088/1742-6596/157/1/012001 
[42] Elzein T., Nasser-Eddine M., Delaite C., Bistac S., Dumas P.: FTIR study of polycaprolactone chain organization at interfaces. Journal of Colloid and Interface Science, 273, 381-387 (2004).

https://doi.org/10.1016/j.jcis.2004.02.001

[43] Shoja M., Kamyar S., Ahmad M. B., Zakaria Z.: Preparation and characterization of poly( $\varepsilon$-caprolactone)/ $\mathrm{TiO}_{2}$ micro-composites. Digest Journal of Nanomaterials and Biostructures, 10, 471-477 (2015).

[44] Boucher D. S.: Solubility parameters and solvent affinities for polycaprolactone: A comparison of methods. Journal of Applied Polymer Science, 137, 48908/148908/13 (2020).

https://doi.org/10.1002/app.48908
[45] Cıplak Z., Yıldız N., Çalımlı A.: Investigation of graphene/Ag nanocomposites synthesis parameters for two different synthesis methods. Fullerenes, Nanotubes and Carbon Nanostructures, 23, 361-370 (2014). https://doi.org/10.1080/1536383X.2014.894025

[46] Stuart B. H.: Infrared spectroscopy: Fundamentals and applications. Wiley, Chichester (2004).

https://doi.org/10.1002/0470011149

[47] Sood S., Gupta V. K., Agarwal S., Dev K., Pathania D.: Controlled release of antibiotic amoxicillin drug using carboxymethyl cellulose-cl-poly(lactic acid-co-itaconic acid) hydrogel. International Journal of Biological Macromolecules, 101, 612-620 (2017).

https://doi.org/10.1016/j.ijbiomac.2017.03.103 